\title{
Burden of oral anticoagulation in embolic stroke of undetermined source without atrial fibrillation
}

\author{
Klaus K. Witte ${ }^{1 *}$, Georgios Tsivgoulis ${ }^{2}$, Matthew R. Reynolds ${ }^{3}$, Stelios I. Tsintzos ${ }^{4}$, Simon Eggington ${ }^{4}$, \\ Eleni Ismyrloglou ${ }^{5}$, Julie Lyon ${ }^{6}$, Marianne Huynh ${ }^{7}$, Marta Egea $^{8}$, Bonnie de Brouwer ${ }^{5}$, Paul D. Ziegler ${ }^{9}$, \\ Noreli Franco ${ }^{9}$, Rashmi Joglekar ${ }^{4}$, Sarah C. Rosemas ${ }^{9}$, Shufeng Liu ${ }^{9}$ and Vincent Thijs ${ }^{10}$
}

\begin{abstract}
Objective: Prevention of recurrent stroke in patients with embolic stroke of undetermined source (ESUS) is challenging. The advent of safer anticoagulation in the form of direct oral anticoagulants (DOACs) has prompted exploration of prophylactic anticoagulation for all ESUS patients, rather than anticoagulating just those with documented atrial fibrillation (AF). However, recent trials have failed to demonstrate a clinical benefit, while observing increased bleeding. We modeled the economic impact of anticoagulating ESUS patients without documented AF across multiple geographies.

Methods: CRYSTAL-AF trial data were used to assess ischaemic stroke event rates in ESUS patients confirmed AF-free after long-term monitoring. Anticipated bleeding event rates (including both minor and major bleeds) with aspirin, dabigatran $150 \mathrm{mg}$, and rivaroxaban $20 \mathrm{mg}$ were sourced from published meta-analyses, whilst a 30\% ischaemic stroke reduction for both DOACs was assumed. Cost data for clinical events and pharmaceuticals were collected from the local payer perspective.

Results: Compared with aspirin, dabigatran and rivaroxaban resulted in 17.9 and 29.9 additional bleeding events per 100 patients over a patient's lifetime, respectively. Despite incorporating into our model the proposed $30 \%$ reduction in ischaemic stroke risk, both DOACs were cost-additive over patient lifetime, as the costs of bleeding events and pharmaceuticals outweighed cost savings associated with the reduction in ischaemic strokes. DOACs added $£ 5953-£ 7018$ per patient (UK), €6683-€7368 (Netherlands), €4933-€9378 (Spain), AUD\$5353-6539 (Australia) and $\$ 26,768-\$ 32,259$ (US) of payer cost depending on the agent prescribed. Additionally, in the U.S. patient pharmacy copayments ranged from $\$ 2468-\$ 12,844$ depending on agent and patient plan. In all settings, cost-savings could not be demonstrated even when the modelling assumed 100\% protection from recurrent ischaemic strokes, due to the very low underlying risk of recurrent ischaemic stroke in this population (1.27 per 100 patient-years).
\end{abstract}

Conclusions: Anticoagulation of non-AF patients may cause excess bleeds and add substantial costs for uncertain benefits, suggesting a personalised approach to anticoagulation in ESUS patients.

${ }^{*}$ Correspondence: k.k.witte@leeds.ac.uk

${ }^{1}$ Leeds Institute of Cardiovascular and Metabolic Medicine, University

of Leeds, LIGHT Building, Clarendon Way, Leeds LS2 9JT, UK

Full list of author information is available at the end of the article

\section{Key messages}

- In ESUS patients from CRYSTAL-AF confirmed as being free of AF with three years of continuous monitoring, the recurrent stroke rate is low such that any 
savings from reduced ischaemic stroke recurrence is likely to be offset by increases in bleeding-related and prescription costs.

- Our results demonstrate that DOACs would generally be cost-additive because of the very low rate of stroke and the additional risk of bleeding.

- In environments with substantial patient participation in hospitalisation and prescription expenses, DOACs in this population may add substantial outof-pocket patient costs for uncertain benefits.

\section{Introduction}

In routine practice, despite comprehensive evaluation, the aetiology of up to $40 \%$ of ischaemic strokes remains unknown. Initially labelled as cryptogenic strokes (CS) $[1,2]$, to reduce heterogeneity diagnostic criteria were refined with most CS cases now termed Embolic Strokes of Undetermined Source (ESUS), representing 32\% of ischaemic stroke cases [3-5].

Intermittent and asymptomatic atrial fibrillation is an aetiological factor for ischaemic stroke. The CRYSTALAF trial [6] showed an AF detection rate of $30.0 \%$ after three years of continuous monitoring with an insertable cardiac monitor (ICM) in patients with CS, higher at $33.6-35.8 \%$ in those patients fulfilling ESUS criteria [7]. Guidelines remain clear on the need for AF patients with sufficient risk factors to be anticoagulated to reduce the risk of primary or recurrent stroke [8-10]. However, until recently, whether anticoagulation might be useful in CS (or ESUS) patients without proven AF was unknown. Randomised controlled clinical trials (RCTs) of mostly warfarin in patients without AF [11-13] had not confirmed a net benefit of anticoagulation in the absence of AF. Specifically, reductions in ischaemic strokes were counteracted by increases in bleeding, leaving aspirin unchallenged as the antithrombotic of choice in the absence of AF. Nevertheless, questions remained about whether safer anticoagulants could improve upon the therapeutic profile of aspirin for stroke prevention.

RCTs have shown that direct oral anticoagulants (DOACs) match or exceed warfarin in efficacy and safety for patients with AF [14-17], and several economic evaluations have determined DOACs to be cost-effective for the prevention of stroke in patients with documented AF, as compared to warfarin or aspirin $[18,19]$. Their improved safety profile over warfarin led to the hypothesis that they were sufficiently safe to be prescribed in patients with risk factors, but without confirmed AF. Recently published trials using dabigatran and rivaroxaban designed to answer this question in the ESUS population reported no overall change in ischaemic stroke rate but increased bleeding [20, 21].
Considering these recent developments, we aimed firstly to provide a plausible prediction, and then explanation, for these results by better understanding the potential clinical impact of DOAC therapy with dabigatran and rivaroxaban in ESUS patients proven not to have AF, using the unique opportunity provided by the CRYSTAL-AF dataset. Secondly, we sought to describe the economic consequences across multiple international settings (the United States (U.S.), United Kingdom (UK), Spain, Netherlands, and Australia) of offering anticoagulation to all ESUS patients.

\section{Methods}

The analysis first required data on event rates per patient per year for recurrent ischaemic stroke and major and minor bleeding events for the ESUS patient population. To project outcomes to patients' lifetimes, and thus understand the consequences of anticoagulating the subgroup of patients with an ESUS but in whom AF has been excluded, we used an existing economic framework by Diamantopoulos et al. [22] based upon data from the CRYSTAL-AF trial of ICMs in a CS patient population.

\section{Clinical event rates}

Recurrent stroke rates were assessed in ESUS patients in the CRYSTAL-AF trial [7] who met the enrollment criteria for both NAVIGATE ESUS [20] and RE-SPECT ESUS [21] studies, in whom no AF of any duration had been detected by the end of follow-up despite 36 months of continuous monitoring. We focused solely on recurrent stroke events and excluded transient ischaemic attacks (TIAs).

Bleeding event rates for dabigatran $150 \mathrm{mg}$ and rivaroxaban $20 \mathrm{mg}$ were sourced from the literature as described by the aforementioned economic framework [22], supplemented with data from a recent network meta-analysis by Tawfik et al. [23] which presented event rates in AF patients enrolled in 16 RCTs with warfarin and DOACs against aspirin. Major bleeds included in the model were haemorrhagic stroke and other intracranial haemorrhage, while minor bleeding included extracranial haemorrhages and clinically-relevant non-major (CRNM) [24] bleeds. To align with the powering assumptions used for the designs of the RESPECT ESUS and NAVIGATE ESUS trials, we assumed that these agents would result in a $30 \%$ relative risk reduction for ischaemic stroke against aspirin. Risks of stroke/bleed events and treatment effects were modeled over the lifetime of the patient, with risks adjusted by a factor of 1.46 and 1.97 per decade age for ischaemic strokes and bleeding events, respectively [20]. 


\section{Long-term clinical projection framework}

The previously described Markov model for ICM use in CS [22] was adapted to be used as a cost-consequence analysis on medication and event costs over a patient lifetime. The aspirin arm of the model was used as the foundation. Baseline characteristics of the patients were equalized with the ESUS subgroup in the CRYSTAL-AF trial: mean age 59.6 years, $58.2 \%$ male, mean $\mathrm{CHADS}_{2}$ score 2.8. Incidence of AF was zeroed since we informed the model using patients free of AF. The model was then run separately for aspirin, rivaroxaban $20 \mathrm{mg}$, and dabigatran $150 \mathrm{mg}$ using the DOAC-specific bleed rates from the literature and assumed ischaemic stroke rates in line with our assumptions as described above. For lack of better data, stroke severity information remained as in the original economic model. Patient survival after recurrent stroke was informed by adjusted survival curves for each of the healthcare environments studied. Details can be found in the Additional file 1: Supplementary Appendix. Discounting of costs and outcomes was applied in-line with the discounting guidelines of each healthcare setting (3-5\% per annum). Due to analytical constraints the model was unable to calculate the effects of more than one recurrent stroke (either an ischaemic or haemorrhagic stroke). For the other event types, including Other ICH, $\mathrm{ECH}$, or CRNM bleeds, patient risks were not limited to one event. The model assumed full adherence to prescribed medications unless a major bleed occurred, following which medications were considered to be stopped.

\section{Cost inputs}

Cost data for clinical events and pharmaceuticals were collected from the local healthcare system perspective for each of the examined environments (U.S., UK, Spain, Netherlands and Australia), and were inflated to 2017 dollars.

For the U.S., medication costs were derived from calendar year 2015-2016 Medicare 100\% data, using the Instant Health Data (IHD) software (Panalgo, Boston MA, U.S.) and R, version 3.2.1. (R Foundation for Statistical Computing, Vienna, Austria). For amounts paid for ischaemic stroke hospitalisations and bleeding events we used 100\% Medicare sample data from 2015-2016. Any extreme outliers were adjusted for by excluding subjects whose costs exceed 1.96 times the standard deviation of the mean cost in each cost extraction, in order to trim data which could be caused by billing data entry errors in the administrative datasets. Long-term (post-90 days) costs for stroke rehabilitation were sourced from the literature [25].
For the UK, stroke hospitalization costs were sourced from the literature [26], 2016-2017 Healthcare Resource Group (HRG) tariffs were used for other bleed-related hospitalisation costs, and 2017 British National Formulary (BNF) data for pharmaceutical pricing. Spanish hospitalisation costs were informed by 2017 data of the Health Information Institute of the Ministry of Health and Social Services (Instituto de Información Sanitaria; Ministerio de Sanidad, Servicios Sociales e Igualdad) and long-term stroke costs from the literature [27]. Dutch hospitalisation costs were sourced from data of the Dutch Healthcare Authority (Nederlandse Zorgautoriteit-NZa) and medication costs were based on the Pharmacy Purchase Price as provided by the Netherlands Costing Institute (Zorginstituut Nederland), both from calendar year 2017. Australian costs were sourced from a recent health technology assessment (HTA) on ICMs in CS [28]. Further details are provided in the Additional file 1: Supplementary Appendix.

\section{Patient economic burden (United States)}

We estimated the economic burden of the examined strategies to patients directly. We identified the level of preference for some of the top private payers currently offering plans in the U.S. (American Association of Retired Professionals "AARP", United Healthcare, Anthem, Aetna) and in combination with IHD cost data estimated the level of co-pay for pharmaceutical prescriptions. For co-payments related to hospitalisations, and to account for out-of-pocket limits to the amount the patient can be held accountable for during one calendar year, we assumed patients had no healthcare resource use unrelated to their original ESUS event.

\section{Results}

\section{Recurrent stroke event rates}

Analysis of the CRYSTAL-AF outcomes data showed that ICM patients with a previous ESUS who met enrollment criteria for NAVIGATE ESUS and RE-SPECT ESUS trials and were free of AF after 36 months of monitoring $(\mathrm{n}=93)$ experienced two strokes over a total follow-up of 1890.5 months, resulting in a stroke rate of 1.27 events (95\% CI 0.15-4.59) per 100 patient-years. In the basecase model extrapolation, $8.8 \%$ of ESUS patients proven free of AF were predicted to have recurrent ischaemic stroke when on aspirin throughout their lifetime. In addition, the model projected that $2.3 \%$ of patients would suffer a haemorrhagic stroke, $1.6 \%$ other intracranial bleeds, and $87.5 \%$ would experience extracranial or CRNM bleeds. 
Table 1 Projected Clinical Events per Patient and over Patient Lifetime in the United Kingdom

\begin{tabular}{llll}
\hline Events over patient lifetime per patient & Aspirin & Dabigatran $150 \mathrm{mg}$ & Rivaroxaban $20 \mathrm{mg}$ \\
\hline Total ischaemic stroke events & 0.08788 & 0.06151 \\
$\triangle$ DOAC vs. Aspirin (Negative=Reduction; Positive=Increase) & & 0.06151 & -0.02636 \\
\% DOAC vs. Aspirin (Negative= Reduction; Positive=Increase) & & -0.02636 & $-30 \%$ \\
Total bleeding events & 0.91371 & $-30 \%$ & 1.21246 \\
$\triangle$ DOAC vs. Aspirin & & 1.09226 & 0.29875 \\
\% DOAC vs. Aspirin & & 0.17855 & $33 \%$ \\
Haemorrhagic stroke & 0.02292 & $20 \%$ & 0.02360 \\
$\triangle$ DOAC vs. Aspirin & & 0.01432 & 0.00069 \\
\% DOAC vs. Aspirin & & -0.00859 & $3 \%$ \\
Other ICH & 0.01549 & $-38 \%$ & 0.01596 \\
$\triangle$ DOAC vs. Aspirin & & 0.01007 & 0.00046 \\
\% DOAC vs. Aspirin & & -0.00542 & $3 \%$ \\
ECH and CRNM bleeds & & $-35 \%$ & 1.17290 \\
$\triangle$ DOAC vs. Aspirin & 0.87530 & 1.06787 & 0.29760 \\
\% DOAC vs. Aspirin & & 0.19257 & $34 \%$ \\
Total events & & $22 \%$ & 1.27397 \\
$\triangle$ DOAC vs. Aspirin & & 1.15377 & 0.27238 \\
\% DOAC vs. Aspirin & 1.00159 & 0.15218 & $27 \%$ \\
\hline
\end{tabular}

Table 1 summarises the projected stroke and bleed events for the United Kingdom. Additional file 1: S5-S8 show the detailed event projections for the other four examined settings. Calculation differs by setting due to minor differences in underlying patient survival

\section{Clinical efficacy}

Table 1 summarises the projected stroke and bleed events for the UK and Additional file 1: Tables S5-S8 show the detailed event projections for the other four examined settings. Based upon the hypothesised 30\% reduction in relative risk of recurrent stroke, use of a DOAC was predicted to be associated with a recurrent ischaemic stroke risk of $6.2 \%$ per patient. However, the model predicted a substantial increase in bleeding rates; a $20 \%$ and $33 \%$ higher rate of bleed events projected with dabigatran and rivaroxaban respectively compared with aspirin, accounting for an additional 17.9-29.9 bleeding events per 100 patients. Over a lifetime, the model projected that all dabigatran and rivaroxaban patients would experience at least 1 serious bleed. The combined rate of stroke and bleeding events was $15 \%$ and $27 \%$ higher with dabigatran and rivaroxaban respectively, compared with aspirin.

\section{Economic endpoints}

Table 2 provides an overview of all costs, by event type, discounted and for every examined healthcare setting. Briefly, DOACs would add between $£ 5953$ and $£ 7018$ per patient (UK), €6683-€7368 (Netherlands), $€ 4933-€ 9378$ (Spain), AUD\$5353-\$6539 (Australia) and $\$ 26,768-\$ 32,259$ (U.S.) from a payer perspective, and were substantially cost-additive under every setting studied, despite the hypothetical $30 \%$ relative risk reduction in recurrent stroke. Under a scenario in which DOACs prevent all recurrent strokes, the model suggests that the strategy would remain cost-additive in all countries (data not shown). The impact of baseline stroke risk was also tested. At the upper confidence level (4.59 strokes per 100 patient-years) of the baseline 1.27 stroke risk, DOACs would remain cost-additive in all geographies. Threshold analysis indicated that the lowest ischaemic stroke risk required in order for DOACs to be cost-saving compared to aspirin was 4.80 strokes per 100 patient-years, though the threshold was highly dependent on the geography and choice of DOAC (Additional file 1: Table S9).

Table 3 presents the co-pays patients in the U.S., insured by various prevalent commercially available plans, would have to bear. Depending on the level of preference in the formulary of each payer, patients would need to bear $\$ 2468.24-\$ 12,844.07$ of pharmaceutical cost.

The total costs associated with DOACs, including pharmaceutical cost plus any bleeds associated with the safety profile of the drugs, were $£ 7438.96$ for Dabigatran $150 \mathrm{mg}$ and $£ 8503.76$ for Rivaroxaban, as compared with aspirin (Table 2). In this population of ESUS patients ultimately found to be free of AF, these costs exceed the expense of long-term ICM monitoring for AF tabulated in the CRYSTAL-AF economic evaluation ( $£ 3088.61$ inclusive of the ICM device, insertion, monitoring, and explant), indicating that a strategy of looking for AF would be economically dominant to an anticoagulate-all approach. 
Table 2 Per-patient Lifetime Costs under the Main Examined Medication Scenarios, by Resource Type and Healthcare Setting

\begin{tabular}{|c|c|c|c|c|c|c|}
\hline & & Aspirin & $\begin{array}{l}\text { Dabigatran } \\
150 \mathrm{mg}\end{array}$ & $\begin{array}{l}\text { Rivaroxaban } \\
20 \mathrm{mg}\end{array}$ & $\triangle$ Dabigatran vs. Aspirin & $\triangle$ Rivaroxaban vs. Aspirin \\
\hline \multirow[t]{4}{*}{ United States } & Ischaemic Strokes & $\$ 8,477.30$ & $\$ 5,934.11$ & $\$ 5,934.11$ & $-\$ 2,543.19$ & $-\$ 2,543.19$ \\
\hline & Bleeding Events & $\$ 31,867.78$ & $\$ 37,443.42$ & $\$ 41,953.51$ & $\$ 5,575.64$ & $\$ 10,085.73$ \\
\hline & Prescriptions & $\$ 259.38$ & $\$ 23,994.99$ & $\$ 24,976.10$ & $\$ 23,735.61$ & $\$ 24,716.72$ \\
\hline & TOTAL & $\$ 40,604.46$ & $\$ 67,372.52$ & $\$ 72,863.72$ & $\$ 26,768.06$ & $\$ 32,259.26$ \\
\hline \multirow[t]{4}{*}{ United Kingdom } & Ischaemic Strokes & $£ 4,953.06$ & $£ 3,467.14$ & $£ 3,467.14$ & $-£ 1,485.92$ & $-£ 1,485.92$ \\
\hline & Bleeding Events & $£ 2,619.19$ & $£ 2,565.92$ & $£ 3,181.65$ & $-£ 53.27$ & $£ 562.46$ \\
\hline & Prescriptions & $£ 123.19$ & $£ 7,615.42$ & $£ 8,064.49$ & $£ 7,492.23$ & $£ 7,941.30$ \\
\hline & TOTAL & $£ 7,695.44$ & $£ 13,648.49$ & $£ 14,713.29$ & $£ 5,953.04$ & $£ 7,017.84$ \\
\hline \multirow[t]{4}{*}{ Netherlands } & Ischaemic Strokes & $€ 1,141.41$ & $€ 798.99$ & $€ 798.99$ & $-€ 342.42$ & $-€ 342.42$ \\
\hline & Bleeding Events & $€ 3,342.24$ & $€ 3,934.81$ & $€ 4,404.05$ & $€ 592.57$ & $€ 1,061.81$ \\
\hline & Prescriptions & $€ 3,173.39$ & $€ 9,605.93$ & $€ 9,821.69$ & $€ 6,432.54$ & $€ 6,648.30$ \\
\hline & TOTAL & $€ 7,657.04$ & $€ 14,339.73$ & $€ 15,024.73$ & $€ 6,682.69$ & $€ 7,367.69$ \\
\hline \multirow[t]{4}{*}{ Spain } & Ischaemic Strokes & $€ 2,377.23$ & $€ 1,664.06$ & $€ 1,664.06$ & $-€ 713.17$ & $-€ 713.17$ \\
\hline & Bleeding Events & $€ 4,640.58$ & $€ 5,299.34$ & $€ 6,029.50$ & $€ 658.76$ & $€ 1,388.92$ \\
\hline & Prescriptions & $€ 986.27$ & $€ 5,974.15$ & $€ 9,689.00$ & $€ 4,987.88$ & $€ 8,702.73$ \\
\hline & TOTAL & $€ 8,004.08$ & $€ 12,937.55$ & $€ 17,382.57$ & $€ 4,933.47$ & $€ 9,378.48$ \\
\hline \multirow[t]{4}{*}{ Australia } & Ischaemic Strokes & AUD\$7,141.27 & AUD\$4,998.89 & AUD\$4,998.89 & - AUD\$2,142.38 & - AUD\$2,142.38 \\
\hline & Bleeding Events & AUD\$6,328.85 & AUD\$6,831.18 & AUD\$8,016.72 & AUD\$502.33 & AUD\$1,687.87 \\
\hline & Prescriptions & AUD\$554.31 & AUD\$7,547.08 & AUD\$7,548.11 & AUD\$6,992.77 & AUD\$6,993.80 \\
\hline & TOTAL & AUD\$14,024.43 & AUD\$19,377.15 & AUD\$20,563.72 & AUD\$5,352.72 & AUD\$6,539.29 \\
\hline
\end{tabular}

Please note the relative reduction of $30 \%$ was assumed equal for dabigatran and rivaroxaban. Note that results would remain cost-additive even if a $100 \%$ reduction in ischaemic strokes vs. aspirin was assumed with the DOACs

Table 3 Patient Out-of-pocket Pharmacy Costs over Lifetime under Various Commercially Available Plans in the U.S

\begin{tabular}{lcc}
\hline Patient plan & $\begin{array}{l}\text { Dabigatran 150 mg } \\
\text { (Pradaxa) } \\
\text { Patient coinsurance }\end{array}$ & $\begin{array}{l}\text { Rivaroxaban } \\
20 \mathrm{mg} \text { (Xarelto) } \\
\text { Patient } \\
\text { coinsurance }\end{array}$ \\
\hline United Healthcare Group Commercial Health Plan (CHP) - coinsurance =20\% & $\$ 2468.24$ & $\$ 2568.81$ \\
United Healthcare Group Preferred Provider Organization (PPO) Plan - coinsurance =20\% & $\$ 2468.24$ & $\$ 2568.81$ \\
Anthem High Deductible Health Plan (HDHP) - coinsurance = 20\% & $\$ 4936.49$ & $\$ 5137.63$ \\
Aetna - coinsurance = 20\% & $\$ 12,341.22$ & $\$ 12,844.07$ \\
American Association of Retired Professionals (AARP) Walgreens Plan - coinsurance =32\% & $\$ 6773.67$ & $\$ 6783.45$ \\
American Association of Retired Professionals (AARP) Preferred Plan - coinsurance $=41 \%$ & $\$ 5059.90$ & $\$ 5266.07$ \\
\hline
\end{tabular}

More information on daily medication costs can be found in Additional file 1: Table S7

Exploratory analysis on patients with confirmed AF While it has been established via the aforementioned CRYSTAL-AF economic analysis [22] that a personalised strategy of oral anticoagulation following a diagnosis of AF made with an ICM was a cost-effective strategy in the cryptogenic stroke/ESUS population, we undertook a threshold analysis to estimate the AF prevalence at which empiric anticoagulation would be economically dominant (that is, superior outcomes at a reduced cost) to a personalised approach. Results indicated that above an AF prevalence of $69.8 \%$ or $76.8 \%$ (for dabigatran and rivaroxaban, respectively), the empiric anticoagulation approach would be the economically dominant strategy compared to a personalised approach. At this point, the benefits of anticoagulation in the entire population, including those without AF, outweigh the costs of monitoring. On the other hand, in a population in whom all have AF, DOACs were estimated to be cost-saving as the reduction in ischemic stroke risk outweighs the cost of potential adverse events and drug costs associated with DOACs. It should be noted that these analyses were reliant on first determining the risk of stroke recurrence in 
the CRYSTAL-AF patients meeting ESUS criteria who were indeed confirmed to have AF $(n=28): 0.066$ strokes per patient-year (95\% CI0.008-0.240). As the precision around this stroke risk estimate was low due to small sample size, these analyses should be viewed as exploratory in nature.

\section{Discussion}

The objective of this study was to analyse the potential clinical and economic impact of DOAC therapy in ESUS patients proven not to have AF, across multiple international settings. The outcomes of our analyses and simulations show that the use of DOACs in ESUS patients without documented AF may come at an excessive risk of additional bleeds or costs or both, with no clear evidence of providing any benefit. The higher costs associated with additional bleeding events and pharmaceuticals may outweigh possible cost savings associated with reductions in the absolute ischaemic stroke risk, which was found to be orders of magnitude lower than the one observed in the presence of AF. These data provide a potential explanation for the recent NAVIGATE ESUS and RE-SPECT ESUS clinical trial results. The hypotheses driving these studies included that AF was frequently undetected and also that patients without proven AF were at increased risk of (embolic) stroke through other pathways. The former hypothesis was confirmed in CRYSTAL-AF and a recent meta-analysis where one-third of continuously monitored ESUS patients had AF [7, 29].

The second hypothesis driving the concept of anticoagulation for all ESUS patients was the debate on whether $\mathrm{AF}$ is the only or main culprit behind CS/ESUS driven by lack of knowledge of the mechanisms underpinning the relationship between $\mathrm{AF}$ and stroke [30], and the role of the left atrial appendage (LAA) as a site of thrombus formation [31], especially in CS. Moreover, several other non-AF mechanisms of stroke potentially benefiting from anticoagulation had been proposed including stasis due to an atrial cardiopathy [27] and artery-to-artery embolism [32, 33]

\section{Pre-DOAC-era studies}

Prior to the development of the DOACs, numerous studies had shown that warfarin did not reduce embolic strokes in patients without clinically-evident AF [11-13]. The Warfarin-Aspirin Recurrent Stroke Study (WARSS) in patients with recent non-cardioembolic ischaemic stroke (including 26\% with CS) showed no additional benefit over aspirin in preventing recurrent ischaemic stroke or death, while the rate of minor haemorrhagic events was greater with warfarin [11]. A common criticism of WARSS was that the study's INR target range of 1.4 to 2.8 included INR values below that considered as therapeutic (typically 2.0-3.0). Whilst it does seem to be case that patients outside the 2.0-3.0 therapeutic range gain less benefit in terms of stroke prevention and suffer more bleeds [34], the Warfarin-Aspirin Symptomatic Intracranial Disease (WASID) trial in patients with stroke or TIA due to intracranial atherosclerotic stenosis also reported no benefit of warfarin in preventing ischaemic stroke, or death, but described higher rates of major haemorrhage despite more accepted INR levels [12]. However, the hazard ratio for ischaemic stroke risk in WASID was directionally supportive.

Subsequently, the Warfarin versus Aspirin in Reduced Cardiac Ejection Fraction (WARCEF) trial provided additional data in patients with heart failure in sinus rhythm [13]. Here also, despite no difference between warfarin and aspirin in the composite primary endpoint of ischaemic stroke, intracerebral haemorrhage, or death, there was a $52 \%$ lower rate of ischaemic stroke in the warfarin arm, albeit offset by an increased risk of major haemorrhage. Although the Aortic Arch Related Cerebral Hazard (ARCH) trial [35] did not show the same trend, overall, these data hinted at the promise of net clinical benefit in a broad spectrum of patients if bleeding risk could be reduced.

\section{Post-DOAC-era studies}

The promising pre-DOAC-era data led to the development of two large studies using dabigatran and rivaroxaban in patients with ESUS. NAVIGATE ESUS [20], comparing rivaroxaban to aspirin, was halted early for futility due to a higher risk of bleeding in the rivaroxaban arm and no evidence of efficacy in preventing either the primary efficacy outcome of recurrent stroke or systemic embolism, or secondary efficacy outcomes. The increased risk conferred by rivaroxaban $(6.5 \times$ that of aspirin for haemorrhagic stroke and $2.34 \times$ for life-threatening and major bleeding in general) was higher than found in our modelling, suggesting that the ESUS population may be at higher bleeding risk than the stroke-free populations with underlying AF collated by Tawfik et al. [24] Another possible explanation is that because follow-up was incomplete when those findings emerged and the decision was reached to stop the trial, the results may have ultimately been less extreme if more follow-up had accrued. On the other hand, the rates of recurrent ischaemic stroke were identical (4.7\%) in the rivaroxaban and aspirin arms. The RE-SPECT ESUS trial [21], comparing dabigatran to aspirin, also found no significant reduction in the primary efficacy endpoint of recurrent stroke which was reduced by $16 \%$ (rather than the anticipated $30 \%$ ), but a significant increase in major and CRNM bleeds in the dabigatran arm. 
Our analysis of ESUS patients from CRYSTAL-AF [7] who were free of AF at 3 years (representing approximately two-thirds of the enrolled ESUS population) showed an annual ischaemic stroke risk of 0.0127 per patient-year, very close to that of the aspirin arm of WARCEF (0.0136 per patient per year). Whereas the control arms of WARSS and WASID had rates of 0.08 and 0.207 ischaemic stroke rates respectively, the aspirin arms of NAVIGATE ESUS and RESPECT-ESUS reported 0.047 per year. There is therefore considerable variability in event rates, implying differences between patients that have not yet been fully explored. Overall however, the data from CRYSTAL-AF suggest that the stroke recurrence rate is very low in the absence of $\mathrm{AF}$, such that the opportunity to reduce stroke via anticoagulation may be limited. Our results demonstrate that DOACs would generally be cost-additive and with the very low rate of stroke, combined with the risk of bleeding, this raises uncertainty on the use of these medications for patients without AF, even if clinical efficacy could be shown.

\section{Personalised care}

On the whole, personalised care, if achievable, leads to heightened outcomes compared to imprecise approaches to therapy. Our modelling, the data from NAVIGATEESUS and RESPECT-ESUS, and recent meta-analysis [36] and observational data [37] on outcomes in patients with long-term monitoring suggest that this paradigm also holds for anticoagulation in patients with CS. For example, the original CRYSTAL-AF economic analysis found that insertable cardiac monitors are a cost-effective tool to diagnose occult $\mathrm{AF}$ and guide appropriate treatment in a CS population [22], with cost-effectiveness further enhanced in subgroups with a slightly higher incidence of AF such as ESUS. While the use of DOACs have been shown to be cost-effective over warfarin and aspirin in a population with proven AF $[18,19]$, our threshold analysis found that in the ESUS population the rate of AF would have to exceed $69.8 \%$ for the empiric anticoagulation strategy be economically dominant (i.e., superior outcomes at a lower cost) compared to a personalised approach. While the rates of underlying AF in the ESUS trials are unknown, existing data show approximately one-third of ESUS patients have AF uncovered after continuous monitoring $[7,29]$ suggesting that what is currently being proposed as standard of care - i.e., use of long-term cardiac monitoring to guide anticoagulation decisions with NOACs - appears to be rational in this population. In combination with the results of the ESUS trials, these results reinforce the logic of actively looking for AF rather than prescribing DOACs to all patients.

\section{Limitations}

The most important limitation to this analysis is that our findings are based on a small sample size with relatively limited follow-up and rely on linked evidence about benefits and harms. Furthermore, the ESUS criteria were applied retrospectively to the CRYSTAL-AF population [7]. However, the necessary diagnostic information was available to perform this re-classification, as a comprehensive stroke work-up was performed at trial entry.

Due to structural constraints, the model is only able to simulate the risk of up to one recurrent ischaemic stroke event after the original ESUS event. Thus, it is possible that patients could experience multiple ischaemic strokes that could be prevented by anticoagulation, which we have not been able to account for. The influence of this would be to reduce the benefit of the treatment effect of empiric anticoagulation, by underestimating the impact of the hypothetical $30 \%$ relative risk reduction. However, with the low observed rate of incident stroke, we expect the actual impact to be small and the direction of our conclusions not to change.

\section{Conclusion}

In a population of patients with unexplained stroke in whom AF has been conclusively excluded through continuous device-based monitoring, our data suggest that empiric anticoagulation in the absence of AF is not clinically or economically useful. Due to the very low underlying rate of recurrent stroke in this patient population, even if DOACs reduced the risk by $30 \%$ as proposed in the design of the recent ESUS trials, DOACs would not be cost-saving. An exploratory threshold analysis suggests that the rate of undiagnosed AF would have to be approximately $70 \%$ for an empiric 'anticoagulate-all' ESUS strategy to offer better outcomes at overall lower cost. These data support the personalised approach of identification of risk factors for stroke (such as AF) and treating these accordingly.

\section{Supplementary Information}

The online version contains supplementary material available at https://doi. org/10.1186/s12872-021-01967-x.

Additional file 1. Supplementary information on patient characteristics, model inputs for mortality rates and unit costs for clinical events/pharmaceuticals, and projected clinical event results by geography.

\section{Acknowledgements \\ None.}

Authors' contributions

All authors contributed to the conception and design of the study, collection and analysis of data and interpretation of results. SIT, SE, EI, RS, JL, RJ, MH, ME, $\mathrm{BdB}, \mathrm{PDZ}, \mathrm{NF}$, and SL were responsible for data collection; SIT, SE, SR, and SL 
carried out the analyses. KWW, GT, VT, and MR provided advice on clinical validation of assumptions and data sources. KWW, NF, SIT, and SR wrote the main manuscript text and prepared data tables. All authors reviewed, edited and approved the manuscript.

\section{Funding}

CRYSTAL-AF and this cost-consequence analysis were funded by Medtronic, Inc.

\section{Availability of data and materials}

The datasets used and/or analysed during the current study available from the corresponding author on reasonable request.

\section{Declaration}

\section{Ethics approval and consent to participate}

The CRYSTAL-AF study (RCT\# NCT00924638) was conducted in accordance with Good Clinical Practice and ISO-14155 as guidance and in compliance with the Declaration of Helsinki and the laws and regulations of the participating countries. Centers provided written approval from the Institutional Review Board and/or Medical Ethics Committee to participate in the study. Informed consent was obtained from all subjects, all of whom were over 18 years of age.

\section{Consent for publication}

Not required; this manuscript does not include details, images, or videos relating to an individual person.

\section{Competing interests}

KKW has received unconditional research funding from Medtronic to the University of Leeds for a PhD Fellowship program and consultancy or speaker fees from Medtronic, Novartis, AstraZeneca, Pfizer, Napp, Abbott, Cardiac Dimensions, and Microport. GT reports no disclosures. VT has received speaker and consultant fees from Boehringer Ingelheim, Bayer, Pfizer, Bristol-Myers Squibb, and Medtronic. MR has received consultancy fees from Medtronic. SIT, SE, EI, RS, JL, RJ, MH, ME, BdB, PDZ, NF, and SL are employees of, and hold shares of, Medtronic.

\section{Author details}

1 Leeds Institute of Cardiovascular and Metabolic Medicine, University of Leeds, LIGHT Building, Clarendon Way, Leeds LS2 9JT, UK. ${ }^{2}$ Second Department of Neurology, "Attikon” University Hospital, National \& Kapodistrian University of Athens Medical School, Athens, Greece. ${ }^{3}$ Baim Institute for Clinical Research, Boston, MA, USA. ${ }^{4}$ Medtronic International Trading Sarl, Tolochenaz, Switzerland. ${ }^{5}$ Medtronic Bakken Research Center B.V., Maastricht, Netherlands. ${ }^{6}$ Medtronic UK and Ireland, Watford, UK. ${ }^{7}$ Medtronic Australasia Pty Ltd, North Ryde, Australia. ${ }^{8}$ Medtronic Spain, Madrid, Spain. ${ }^{9}$ Medtronic Global CRHF Headquarters, Mounds View, MN, USA. ${ }^{10}$ Florey Institute of Neuroscience, Melbourne, Australia.

Received: 18 December 2020 Accepted: 23 March 2021

Published online: 31 March 2021

\section{RefERENCES}

1. Adams HP Jr., Bendixen BH, Kappelle LJ, Biller J, Love BB, Gordon DL, et al. Classification of subtype of acute ischemic stroke. Definitions for use in a multicenter clinical trial. TOAST. Trial of Org 10172 in Acute Stroke Treatment. Stroke 1993;24(1):35-41.

2. Landau WM, Nassief A. Editorial comment-time to burn the TOAST. Stroke. 2005;36(4):902-4.

3. Li L, Yiin GS, Geraghty OC, Schulz UG, Kuker W, Mehta Z, et al. Incidence, outcome, risk factors, and long-term prognosis of cryptogenic transient ischaemic attack and ischaemic stroke: a population-based study. Lancet Neurol. 2015;14(9):903-13.

4. Perera KS, Sharma M, Connolly SJ, Wang J, Gold MR, Hohnloser SH, et al. Stroke type and severity in patients with subclinical atrial fibrillation: an analysis from the Asymptomatic Atrial Fibrillation and Stroke Evaluation in Pacemaker Patients and the Atrial Fibrillation Reduction Atrial Pacing Trial (ASSERT). Am Heart J. 2018;201:160-3.
5. Hart RG, Diener HC, Coutts SB, Easton JD, Granger CB, O'Donnell MJ, et al. Embolic strokes of undetermined source: the case for a new clinical construct. Lancet Neurol. 2014;13(4):429-38.

6. Sanna T, Diener HC, Passman RS, Di Lazzaro V, Bernstein RA, Morillo CA, et al. Cryptogenic stroke and underlying atrial fibrillation. N Engl J Med. 2014;370(26):2478-86.

7. Verma N, Ziegler PD, Liu S, Passman RS. Incidence of atrial fibrillation among patients with an embolic stroke of undetermined source: Insights from insertable cardiac monitors. Int J Stroke. 2018;14(2):146-53.

8. Valentin F, Lars ER, David SC, Harry JC, Anne BC, Kenneth AE, et al. ACC/ AHA/ESC 2006 guidelines for the management of patients with atrial fibrillation 2014: executive summary. Circulation. 2006;114(7):700-52.

9. Craig TJ, Wann LS, Hugh C, Lin YC, Joaquin EC, Joseph CC, et al. 2019 AHA ACC/HRS focused update of the 2014 AHA/ACC/HRS guideline for the management of patients with atrial fibrillation. Circulation 2019.

10. Ahlsson A, Casadei B, Van Putte B, Popescu BA, Atar D, et al. 2016 ESC Guidelines for the management of atrial fibrillation developed in collaboration with EACTS. Eur Heart J. 2016;37(38):2893-962.

11. Mohr JP, Thompson JL, Lazar RM, Levin B, Sacco RL, Furie KL, et al. A comparison of warfarin and aspirin for the prevention of recurrent ischemic stroke. N Engl J Med. 2001;345(20):1444-51.

12. Chimowitz MI, Lynn MJ, Howlett-Smith H, Stern BJ, Hertzberg VS, Frankel MR, et al. Comparison of warfarin and aspirin for symptomatic intracranial arterial stenosis. N Engl J Med. 2005;352(13):1305-16.

13. Homma S, Thompson JL, Pullicino PM, Levin B, Freudenberger RS, Teerlink $J R$, et al. Warfarin and aspirin in patients with heart failure and sinus rhythm. N Engl J Med. 2012;366(20):1859-69.

14. Connolly SJ, Ezekowitz MD, Yusuf S, Eikelboom J, Oldgren J, Parekh A, et al. Dabigatran versus warfarin in patients with atrial fibrillation. J Med. 2009;361(12):1139-51.

15. Patel MR, Mahaffey KW, Garg J, Pan G, Singer DE, Hacke W, et al. Rivaroxaban versus warfarin in nonvalvular atrial fibrillation. J Med. 2011;365(10):883-91.

16. Granger CB, Alexander JH, McMurray JJV, Lopes RD, Hylek EM, Hanna M, et al. Apixaban versus warfarin in patients with atrial fibrillation. J Med. 2011;365(11):981-92.

17. Giugliano RP, Ruff CT, Braunwald E, Murphy SA, Wiviott SD, Halperin JL, et al. Edoxaban versus warfarin in patients with atrial fibrillation. J Med. 2013;369(22):2093-104.

18. López-López JA, Sterne JA, Thom HH, et al. Oral anticoagulants for prevention of stroke in atrial fibrillation: systematic review, network metaanalysis, and cost effectiveness analysis. BMJ. 2017;359:j5058.

19. Liberato NL, Marchetti M. Cost-effectiveness of non-vitamin K antagonist oral anticoagulants for stroke prevention in non-valvular atrial fibrillation: a systematic and qualitative review. Expert Rev Pharmacoecon Outcomes Res. 2016;16(2):221-35.

20. Hart RG, Sharma M, Mundl H, Kasner SE, Bangdiwala SI, Berkowitz SD, et al. Rivaroxaban for stroke prevention after embolic stroke of undetermined source. N Engl J Med. 2018;378(23):2191-201.

21. Diener HC, Sacco RL, Easton JD, Granger CB, Bernstein RA, Uchiyama S, et al. Dabigatran for prevention of stroke after embolic stroke of undetermined source. N Engl J Med. 2019;380(20):1906-17.

22. Diamantopoulos A, Sawyer LM, Lip GY, Witte KK, Reynolds MR, Fauchier $L$, et al. Cost-effectiveness of an insertable cardiac monitor to detect atrial fibrillation in patients with cryptogenic stroke. Int J Stroke. 2016;11(3):302-12.

23. Tawfik A, Bielecki JM, Krahn M, Dorian P, Hoch JS, Boon H, et al. Systematic review and network meta-analysis of stroke prevention treatments in patients with atrial fibrillation. Clin Pharmacol. 2016;8:93-107.

24. Kaatz S, Ahmad D, Spyropoulos AC, Schulman S, the Subcommittee on Control of A. Definition of clinically relevant non-major bleeding in studies of anticoagulants in atrial fibrillation and venous thromboembolic disease in non-surgical patients: communication from the SSC of the ISTH. J Thrombosis Haemostasis. 2015;13(11):2119-26.

25. Shireman TI, Wang K, Saver JL, Goyal M, Bonafe A, Diener HC, et al. Cost-Effectiveness of Solitaire Stent Retriever Thrombectomy for Acute Ischemic Stroke: Results From the SWIFT-PRIME Trial (Solitaire With the Intention for Thrombectomy as Primary Endovascular Treatment for Acute Ischemic Stroke). Stroke. 2017;48(2):379-87.

26. Luengo-Fernandez R, Paul NL, Gray AM, et al. Population-based study of disability and institutionalization after transient ischemic 
attack and stroke: 10-year results of the Oxford Vascular Study. Stroke. 2013;44:2854-61.

27. Baron Esquivias G, Escolar Albaladejo G, Zamorano JL, Betegon Nicolas L, Canal Fontcuberta C, de Salas-Cansado M, et al. Cost-effectiveness analysis comparing apixaban and acenocoumarol in the prevention of stroke in patients with nonvalvular atrial fibrillation in Spain. Rev Esp Cardiol (Engl Ed). 2015;68(8):680-90.

28. Australian Medical Services Advisory Committee (MSAC). Public Summary Document: Implantable loop recorders for diagnosis of atrial fibrillation in cryptogenic stroke. Published April 7, 2017. Available at: http:// www.msac.gov.au/internet/msac/publishing.nsf/Content/1443-public.

29. Tsivgoulis G, Katsanos AH, Köhrmann M, Caso V, Perren F, Palaiodimou L, Deftereos S, Giannopoulos S, Ellul J, Krogias C, Mavridis D, Triantafyllou S, Alexandrov AW, Schellinger PD, Alexandrov AV. Duration of implantable cardiac monitoring and detection of atrial fibrillation in ischemic stroke patients: a systematic review and meta-analysis. J Stroke. 2019;21(3):302-11.

30. Kamel H, Okin PM, Elkind MS, ladecola C. Atrial fibrillation and mechanisms of stroke: time for a new model. Stroke. 2016;47(3):895-900.

31. Yaghi S, Song C, Gray WA, Furie KL, Elkind MS, Kamel H. Left atrial appendage function and stroke risk. Stroke. 2015;46(12):3554-9.

32. Tsivgoulis G, Katsanos AH, Köhrmann M, Caso V, Lemmens R, Tsioufis $K$, Paraskevas GP, Bornstein NM, Schellinger PD, Alexandrov AV, Krogias C. Embolic strokes of undetermined source: theoretical construct or useful clinical tool? Ther Adv Neurol Disord. 2019;12:1756286419851381.
33. Kamel H, Merkler AE, ladecola C, Gupta A, Navi BB. Tailoring the approach to embolic stroke of undetermined source: a review. JAMA Neurol. 2019;76:855-61.

34. White HD, Gruber M, Feyzi J, Kaatz S, Tse HF, Husted S, et al. Comparison of outcomes among patients randomized to warfarin therapy according to anticoagulant control: results from SPORTIF III and V. Arch Intern Med. 2007;167(3):239-45.

35. Amarenco P, Davis S, Jones EF, Cohen AA, Heiss WD, Kaste M, Laouénan C, Young D, Macleod M, Donnan GA, Aortic Arch Related Cerebral Hazard Trial Investigators. Clopidogrel plus aspirin versus warfarin in patients with stroke and aortic arch plaques. Stroke. 2014;45(5):1248-57.

36. Tsivgoulis G, Katsanos AH, MacGrory B, et al. Prolonged Cardiac Rhythm Monitoring and Secondary Stroke Prevention in Patients With Cryptogenic Cerebral Ischemia. Stroke. 2019;50:1-6.

37. Triantafyllou S, Katsanos AH, Dilaveris $\mathrm{P}$, et al. Implantable cardiac monitoring in the secondary prevention of cryptogenic stroke. Ann Neurol. 2020;88(5):946-55.

\section{Publisher's Note}

Springer Nature remains neutral with regard to jurisdictional claims in published maps and institutional affiliations.
Ready to submit your research? Choose BMC and benefit from:

- fast, convenient online submission

- thorough peer review by experienced researchers in your field

- rapid publication on acceptance

- support for research data, including large and complex data types

- gold Open Access which fosters wider collaboration and increased citations

- maximum visibility for your research: over 100M website views per year

At BMC, research is always in progress.

Learn more biomedcentral.com/submissions 


\section{University Library}

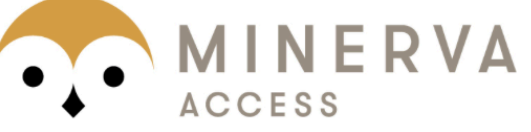

A gateway to Melbourne's research publications

Minerva Access is the Institutional Repository of The University of Melbourne

\section{Author/s:}

Witte, KK;Tsivgoulis, G;Reynolds, MR;Tsintzos, SI;Eggington, S;Ismyrloglou, E;Lyon, J;Huynh, M;Egea, M;de Brouwer, B;Ziegler, PD;Franco, N;Joglekar, R;Rosemas, SC;Liu, S;Thijs, V

Title:

Burden of oral anticoagulation in embolic stroke of undetermined source without atrial fibrillation

\section{Date:}

2021-03-31

\section{Citation:}

Witte, K. K., Tsivgoulis, G., Reynolds, M. R., Tsintzos, S. I., Eggington, S., Ismyrloglou, E., Lyon, J., Huynh, M., Egea, M., de Brouwer, B., Ziegler, P. D., Franco, N., Joglekar, R., Rosemas, S. C., Liu, S. \& Thijs, V. (2021). Burden of oral anticoagulation in embolic stroke of undetermined source without atrial fibrillation. BMC CARDIOVASCULAR DISORDERS, 21 (1), https://doi.org/10.1186/s12872-021-01967-x.

Persistent Link:

http://hdl.handle.net/11343/277974

License:

CC BY 